Tjalling C. Koopmans Research Institute Tplligh Aoopman

Discussion Paper Series nr: 04-28

\title{
Growing Old and Staying Young: Population Policy in an Ageing Closed Economy
}

Bas van Groezen

Lex Meijdam 


\section{Tjalling C. Koopmans Research Institute Utrecht School of Economics \\ Utrecht University}

Vredenburg 138

3511 BG Utrecht

The Netherlands

telephone $\quad+31302539800$

fax $\quad+31302537373$

website www.koopmansinstitute.uu.nl

The Tjalling C. Koopmans Institute is the research institute and research school of Utrecht School of Economics.

It was founded in 2003, and named after Professor Tjalling C. Koopmans, Dutch-born Nobel Prize laureate in economics of 1975.

In the discussion papers series the Koopmans Institute publishes results of ongoing research for early dissemination of research results, and to enhance discussion with colleagues.

Please send any comments and suggestions on the Koopmans institute, or this series to M.Damhuis@econ.uu.nl

ontwerp voorblad: WRIK Utrecht

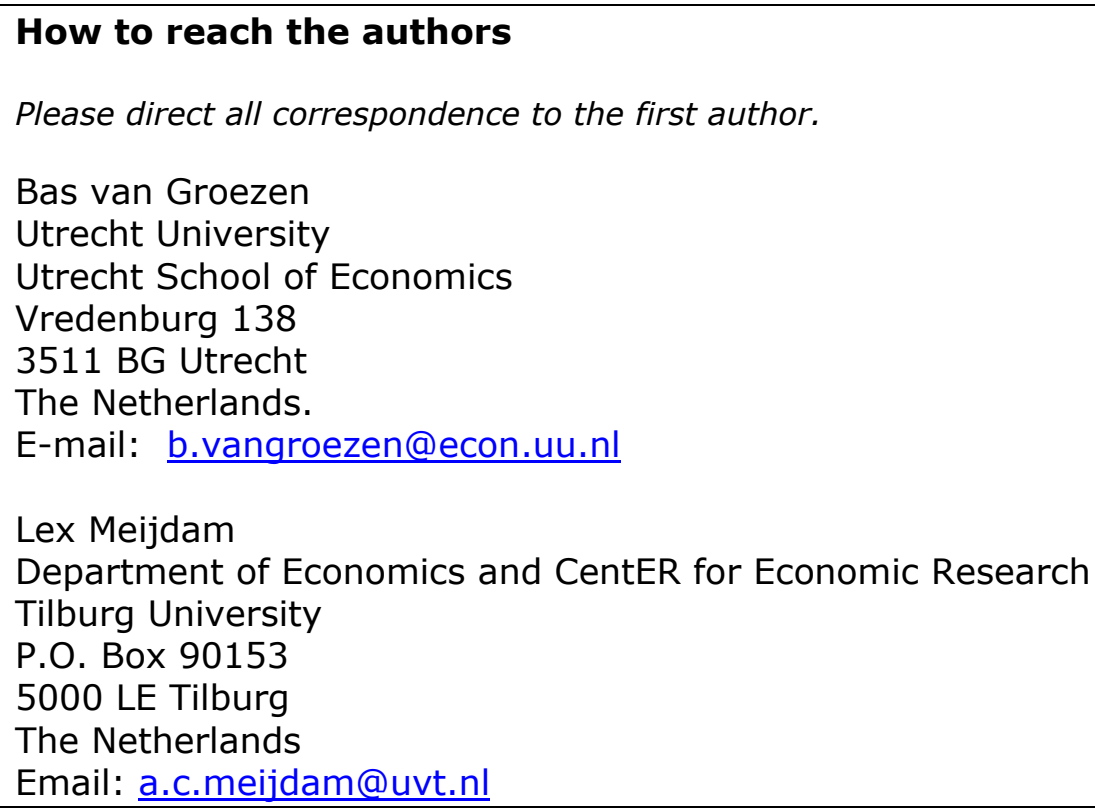


Utrecht School of Economics

Tjalling C. Koopmans Research Institute

Discussion Paper Series 04-28

\title{
Growing Old and Staying Young: Population Policy in an Ageing Closed Economy
}

\author{
Bas van Groezena \\ Lex Meijdamb \\ aUtrecht School of Economics \\ Utrecht University \\ ${ }^{b}$ Department of Economics and CentER for Economic Research \\ Tilburg University \\ November 2004
}

\begin{abstract}
This paper analyses the relation between public pensions, fertility and child care in a closed economy OLG-model with endogenous fertility. It it shown that it is optimal to introduce child allowances if the government redistributes income from the young to the old, and rises when longevity increases.
\end{abstract}

Keywords: ageing, child allowances, closed economy, endogenous fertility, overlapping generations, pensions, social security

JEL classification: D10, H55, J13, J14, J18, J26 


\section{Introduction}

Population ageing raises widespread concern about the sustainability of existing social security programs, notably public pension systems that are run on a pay-as-you-go (PAYG) basis. The emphasis in the current debate among economists and politicians is therefore mostly put on the appropriate way of reforming the pension system so as to dismantle the 'demographic time bomb'. Though nobody doubts the necessity of adjusting pension arrangements to the changing social circumstances, it is striking that neither the cause of the low rate of fertility, which is one of the main true causes of ageing, nor measures to tackle it receive much attention in the economic literature. This paper aims to partly fill this gap by analysing the relation between social security, fertility and child care in a closed economy. Fertility is treated as an endogenous economic variable, that is, as the result of individuals' decisions on how many children to raise.

The economic approach to fertility was introduced by Leibenstein (1957) and Becker (1961), who postulated that the number of children directly enters the utility function, just like consumption goods do. ${ }^{1}$ The so-called old-age security hypothesis (Cigno, 1992) stresses that, apart from giving instantaneous utility, offspring can also be viewed as a kind of capital good that enhances utility later in life by serving as an insurance against the risk of old-age dependency. However, in the second half of the last century, old-age care has been institutionalised in many developed countries through the installation and extension of public pension and health care arrangements. As a result, the old-age security hypothesis is less relevant: raising a child does not 'pay out' to the individual parent herself any more. This is one of the reasons for the dramatic drop in the fertility rate. ${ }^{2}$ Instead of an individual return, children now have a return to society as a whole. However, this social externality is not taken into account when fertility choices are made (see e.g. Cigno, 1993, and

\footnotetext{
${ }^{1}$ According to Zhang and Zhang (1998), this can be viewed as a weak form of altruism towards children. Alternatively, much as in e.g. Razin and Ben-Zion (1975) and Zhang (1995), parents could also derive direct utility from the utility of their offspring, which can be considered complete or strong altruism.

${ }^{2}$ This is confirmed by Cigno and Rosati (1996) and Cigno et al. (2003) who investigate the cases of Germany, Italy, the UK, and the US. Another reason is that women got better labour force opportunities and (real) wages increased, so that the opportunity costs of raising children increased. See e.g. Becker and Barro (1988) and Galor and Weil (1996).
} 
Folbre, 1994, who typifies offspring as a public rather than a private 'capital good'). A PAYG-pension scheme thus creates an incentive for an individual to free ride on the public system by raising few children, while still being entitled to a retirement benefit (see e.g. Sinn, 1997). This distortion can be corrected by making pensions partly contingent upon fertility (Sinn, 2004) or by introducing child allowances. Groezen et al. (2003) analyse the latter instrument in a small open economy model and show that PAYG-pensions and child allowances are Siamese twins: if the government wants to redistribute from the young to the old, it is optimal to also introduce child allowances to correct the external effect caused by the PAYG-scheme. In particular, they show that the optimal subsidy to parents is equal to the present value of a child's contribution to the intergenerational redistribution scheme during his working life. In the current paper, we analyse the relation between social security, fertility and child care in a closed economy and may therefore be viewed as a generalisation of Groezen et al. (2003). Indeed, we show that PAYG-pensions and child allowances are Siamese twins also in closed economy and that the optimal level of the child allowance equals the child's contribution to the PAYG-scheme discounted at the interest rate that results in the optimum. However, we also show that there is an important difference between a closed and a small open economy: in a closed economy the optimal level of the PAYG-tax and the accompanying child allowance falls when the social discount factor rises, whereas it increases in a small open economy.

The current paper is not merely a generalisation of Groezen et al. (2003) to a closed economy, but adds to that by analysing the effects of an increase in average life span. That is, we not only investigate how the decisions of an individual deviate from the social optimum and in what way a government can intervene to improve welfare, but we also study how one form of ageing, viz. increasing longevity, affects the rate of fertility. It turns out that this effect is ambiguous: in a closed economy, the negative effect of increasing longevity on fertility that exists in an open economy (see Groezen et al., 2002) is reinforced by a positive income effect as the capitallabour ratio increases, but it may also be offset by the negative general-equilibrium effect that this generates. Finally, we show that, provided a weak condition holds, increasing longevity implies a higher optimal level of child allowance and a higher optimal PAYG-tax.

The rest of the paper is organised as follows. In Section 2, the model is presented. Section 3 analyses the results of an increase in life span. In Section 4 the first-best 
solution is derived and Section 5 shows that this solution can be realised in a market economy using both child allowances and PAYG-pensions (or a tax on children in combination with redistribution from the old to the young). Moreover, increasing longevity implies a higher optimal child allowance. Section 6 concludes.

\section{The model}

Consider a closed economy where production is described by a standard neoclassical constant-returns-to-scale production function, $f\left(k_{t}\right)$, with $k_{t}$ the amount of capital per young individual in period $t$. The interest rate and wage are given by, respectively, $r_{t}=f^{\prime}\left(k_{t}\right) \equiv \frac{d f\left(k_{t}\right)}{d k_{t}}$ and $w_{t}=f\left(k_{t}\right)-k_{t} f^{\prime}\left(k_{t}\right)$. The economy is populated by a large number of individuals who live for at most two periods, such that in each period, both a young and an old generation are alive. Apart from age, individuals are identical. Every young person faces a probability $\varepsilon$ of growing old, so $1-\varepsilon$ is the fraction of young that die after one period of life.

All young individuals inelastically supply one unit of labour. The government imposes a constant proportional tax $\tau$ on labour income so as to finance public pension benefits received by the current elderly. The remainder of first-period income is either spent on material consumption $\left(c^{y}\right)$ and offspring $(n)$, or is saved for old age $(s)$. Raising a child directly increases the individual's utility, but also entails a cost $p$, which not only consists of commodities like food and clothes, but to a great extent also of services such as education and child care (or the foregone wage income if a parent decides to take care of the child him/herself). We therefore assume $p$ to be a positive function of the current wage: $p_{t}=p\left(w_{t}\right)$, with $p^{\prime} \equiv \frac{d p}{d w}>0$. Consequently, first-period consumption is restricted by the following budget constraint,

$$
c_{t}^{y}+p\left(w_{t}\right) n_{t}=w_{t}(1-\tau)-s_{t}
$$

If an individual survives to the second period of life, she is retired and derives utility from old-age (material) consumption $\left(c^{o}\right),{ }^{3}$ which is financed from the return on

\footnotetext{
${ }^{3}$ If she derived utility from children too, the main results would still hold as long as the marginal utility from children in the second period of life is not greater than in the first period of life. This is a reasonable assumption since the utility one derives from children depends to a great extent on the time spent together with them, which is most during the childhood years, i.e. when parents are young.
} 
first-period savings and a public PAYG-pension benefit $(\eta)$. We assume agents to have perfect foresight with respect to the level of the future public pension benefit. Savings are invested in annuities or through an actuarially fair pension fund. As only a fraction $\varepsilon$ of young savers survive to the next period, the assets of those who passed away fall to surviving contemporaries. The return on the savings, assuming full depreciation of capital after one period, ${ }^{4}$ is therefore equal to $\frac{r}{\varepsilon}$, so the second-period budget constraint can be written as

$$
c_{t+1}^{o}=\frac{r_{t+1}}{\varepsilon} s_{t}+\eta_{t+1}
$$

Young people derive utility from the number of children they raise $\left(n_{t}\right)$ and material consumption $\left(c_{t}^{y}\right)$, whereas the retired value material consumption $\left(c_{t+1}^{o}\right)$ only, as mentioned above. For analytical convenience, we assume the utility function of a representative individual to be additively separable and the felicity functions to be logarithmic,

$$
U\left(c_{t}^{y}, n_{t}, c_{t+1}^{o}\right)=\log \left(c_{t}^{y}\right)+\gamma \log \left(n_{t}\right)+\beta \varepsilon \log \left(c_{t+1}^{o}\right),
$$

where $\beta$ is the private discount rate and $\gamma$ the utility weight of raising children relative to material consumption. ${ }^{5}$

The government runs the public pension system as a PAYG-scheme, implying that

$$
\varepsilon \eta_{t}=n_{t-1} \tau w_{t}
$$

Since the public pension benefit is equal for all retired in a certain generation, and therefore does not directly depend on the number of children one has raised, individuals do not take the government budget constraint into account when making their fertility decision. Put differently, the so-called old-age security hypothesis does not play a role in the individual's choice, though it still holds for society as a whole. As a consequence, this allows people to free ride on the system by rearing few children (or none at all) and still being entitled to a full pension benefit (see e.g. Cigno, 1993, and Folbre, 1994).

\footnotetext{
${ }^{4}$ Any rate of depreciation could be assumed, but would not affect the results.

${ }^{5}$ This is a conventional way of modelling endogenous fertility. See e.g. Eckstein and Wolpin (1985) and Galor and Weil (1996).
} 
Individuals maximise utility (2) subject to their budget constraints (1.a) and (1.b), which gives the following individual first-order conditions,

$$
\begin{aligned}
c_{t+1}^{o} & =r_{t+1} \beta c_{t}^{y}, \\
p\left(w_{t}\right) n_{t} & =\gamma c_{t}^{y} .
\end{aligned}
$$

According to (4.a), households equate the marginal rate of substitution between current and future consumption to the rate of interest, and according to (4.b), households choose the number of children and consumption in their first period of life such that the marginal rate of substitution between a child and current consumption equals the marginal cost of rearing an extra child. From (1.a), (1.b), (3), (4.a) and (4.b) we can derive the steady state, ${ }^{6}$

$$
\begin{aligned}
c^{y} & =\frac{w(1-\tau) p(w) r}{(1+\gamma+\beta \varepsilon) p(w) r-\gamma \tau w} \\
n & =\frac{\gamma w(1-\tau) r}{(1+\gamma+\beta \varepsilon) p(w) r-\gamma \tau w} \\
s & =\frac{w(1-\tau)[\beta \varepsilon p(w) r-\gamma \tau w]}{(1+\gamma+\beta \varepsilon) p(w) r-\gamma \tau w}
\end{aligned}
$$

\section{Effects of increasing longevity}

Nearly all industrialised countries will experience an ageing population, caused by lower fertility rates and an increasing life span. This will not only have important implications for pension systems, but also factor rewards and the rate of fertility itself will be influenced by the demographic change. The purpose of this section is to analyse how fertility behaviour changes in a closed economy where people expect to live longer.

In a closed economy, savings are entirely invested domestically. Equilibrium in the capital market is therefore given by

$$
s_{t}=n_{t} k_{t+1}
$$

So the capital-labour ratio is the result of both the individual savings and fertility choices. This in turn determines the wage and interest rate on which economic agents

\footnotetext{
${ }^{6}$ Whenever time subscripts are omitted, we refer to the steady-state value of the respective variable.
} 
base their decisions. Because the expected lifespan is an important determinant of savings, increasing longevity affects several economic variables, as described by the following proposition.

Proposition 1 If the (expected) life span increases in a closed economy, the long-run capital-labour ratio increases. The number of children may increase or decrease in the long run.

Proof Inserting (5) into (1.a) and combining with (6) gives the implicit solution of $k$,

$$
\beta \varepsilon p(w) r-\gamma \tau w=\gamma r k .
$$

Comparative statics gives $\frac{\partial k}{\partial \varepsilon}=\frac{\beta p(w)(1+r)^{2}}{\gamma\left[r^{2}-\tau k f^{\prime \prime}(k) r-\tau w f^{\prime \prime}(k)\right]}>0$. From this it follows that $\frac{\partial r}{\partial \varepsilon}<0$ and $\frac{\partial w}{\partial \varepsilon}>0$. The change in the number of children due to a longer life span is given by

$$
\begin{aligned}
\frac{\partial n}{\partial \varepsilon}=\frac{n}{\Delta}\{ & -\beta p(w) r+(1+\gamma+\beta \varepsilon) p(w) r\left(p(w)-w p^{\prime}(w)\right) \frac{\partial w / \partial \varepsilon}{w} \\
& \left.-\gamma \tau w \frac{\partial r / \partial \varepsilon}{r}\right\}
\end{aligned}
$$

with $\Delta \equiv(1+\gamma+\beta \varepsilon) p(w) r-\gamma \tau w>0$. The first term between brackets is negative, the second term is positive if $\frac{d p / p}{d w / w}<1$, whereas the last term is positive. Hence, the number of children can decrease or increase due to a longer lifespan.

Increasing longevity urges people to save more, which initially implies lower expenses on consumption when young and also on the number of children. So in the short run, fertility decreases. The higher savings are invested domestically, so that in subsequent periods, the capital stock increases. This, together with a smaller population growth, implies a higher capital-labour ratio. As a result, the wage increases, which causes both a positive income effect on the number of children, and a higher price of raising a child, which affects fertility negatively. Furthermore, the interest rate decreases, so the present value of the public pension benefit increases, so that individuals save less and raise more children. The general-equilibrium effects may eventually dominate the direct negative effect, ${ }^{7}$ though this is not very likely. In a small open economy, these

\footnotetext{
${ }^{7}$ For instance if the capital-labour ratio is initially quite low (e.g. due to an extensive unfunded pension scheme), the marginal product of capital will be high. Consequently, a growing capital stock will induce a substantial wage increase, boosting the fertility rate. The same applies if capital and labour are weak substitutes in the production process.
} 
general-equilibrium effects do not occur, and the number of children unambiguously decreases due to an increasing life span (see Groezen et al., 2002).

\section{The first-best solution}

In the model of endogenous fertility presented above, the only reason for people to raise children is the direct utility they get from it. The fact that their children will also participate in the labour market one period later and consequently increase production is thus neglected. This section therefore explores the externalities that a child brings about for society as a whole, by comparing the choices that individuals make in a market setting to the choice that a social planner would make.

Consider a social planner at time $t$ whose objective function consists of the lifetime utilities of all current and future generations,

$$
W_{t}=\sum_{i=t}^{\infty} \delta^{i-t} U\left(c_{i-1}^{y}, n_{i-1}, c_{i}^{o}\right),
$$

where $\delta<1$ is the social discount factor, i.e. the factor at which the planner discounts lifetime utility of future generations.

In every period, total production is allocated to consumption of the young and old, the costs of rearing children and domestic investments. The social planner is therefore restricted by the economy's resource constraint,

$$
f\left(k_{t}\right)=c_{t}^{y}+p\left(w_{t}\right) n_{t}+\frac{\varepsilon c_{t}^{o}}{n_{t-1}}+n_{t} k_{t+1} .
$$

Maximising (7) at time $t$ subject to (8) results in the following first-order conditions for the command optimum,

$$
\begin{aligned}
\frac{c_{t+1}^{y *}}{c_{t}^{y *}} & =\frac{\delta\left(r_{t+1}^{*}+n_{t+1}^{*} p^{\prime}\left(w_{t}^{*}\right) k_{t}^{*} f^{\prime \prime}\left(k_{t}^{*}\right)\right)}{n_{t}^{*}} \\
\frac{c_{t}^{y *}}{n_{t}^{*}} & =\frac{p\left(w_{t}^{*}\right)+k_{t+1}^{*}}{\gamma+\beta \varepsilon} \\
\frac{c_{t}^{o *}}{c_{t}^{y *}} & =\frac{\beta n_{t-1}^{*}}{\delta}
\end{aligned}
$$

where $x^{*}$ denotes the socially optimal value of variable $x$. Combining (9.a) and (9.c) gives

$$
\frac{c_{t+1}^{o *}}{c_{t}^{y *}}=\beta\left(r_{t+1}^{*}+n_{t+1}^{*} p^{\prime}\left(w_{t}^{*}\right) k_{t}^{*} f^{\prime \prime}\left(k_{t}^{*}\right)\right)
$$


Comparing the first-order conditions of individual households and the social planner indicates several reasons why the actual number of children that households raise may not coincide with the socially optimal fertility rate. Equation (9.b) differs from (4.b) in two ways. First, a child will contribute to the economy's production when it has grown to maturity. This extra output will be shared with all people alive in that period, including the child's parents. However, the parents do not take this effect into account when they make their fertility decision, as they will only receive a small part of this production when they are retired. This positive social externality of a child implies that too few children are born. Second, however, an extra child also implies that a higher capital stock is required in order to keep future per capita production at the same level. Since in a closed economy, the capital stock is financed with national savings, parents should save an extra amount for each additional child they raise. Put differently, every extra child implies a smaller capital-labour ratio. This capital-dilution effect can be considered a negative social externality that an individual does not consider, and therefore would imply that fertility is above the social optimum.

The third deviation of the market outcome from the social optimum concerns the intertemporal allocation. As can be seen from comparing (4.a) to (9.d), individuals tend to transfer less income from the first period to their second period of life if $p^{\prime}>0$. Savings do not only imply that future income increases by the marginal product of capital, i.e. the interest rate, but it also implies that the wage, and thus the cost of raising a child, rise. This causes both a negative income and substitution effect on the future fertility rate, which an individual does not take into account in the savings decision. Note that this effect does not occur in a small open economy where the capital-labour ratio is determined on the world capital market, implying an exogenous wage and child raising costs.

The number of children in a market economy may therefore be too low or too high as compared to the command optimum, depending on which of the effects dominate. Clearly, since both the fertility and savings decision typically do not coincide with the social planner's choice, the government needs two policy instruments to correct the market failures. 


\section{Child allowances and public pensions}

In order to analyse the optimal policy instruments, we will assume a Cobb-Douglas production function, $f(k)=k^{\alpha}$, so $r=\alpha k^{\alpha-1}$. Furthermore, the price of children is a linear function of the wage, $p_{t}=\lambda w_{t}=\lambda(1-\alpha) k^{\alpha}$.

If both offspring and savings deviate from the social optimum, the government needs two instruments to correct this. Since offspring can be considered a normal good, a decrease of its price due to a subsidy per child would induce people to have more children. $^{8}$ In the opposite case it would need a tax on children so that the number of children that parents decide to raise decreases. Moreover, individual savings can be influenced by intergenerational transfers, which in our model occurs through the PAYG-pension scheme. ${ }^{9}$

Suppose the government contributes a fraction $\varphi$ towards the costs of raising children, which cannot only be thought of as a (direct) child benefit, but also involves e.g. subsidizing child care, public education and student grants. These allowances are financed by a proportional wage tax of $\theta$. The individual's first-period budget constraint then becomes

$$
c_{t}^{y}+(1-\varphi) p\left(w_{t}\right) n_{t}=\left(1-\tau-\theta_{t}\right) w_{t}-s_{t},
$$

and the government's budget constraint for the child allowance scheme is

$$
\theta_{t} w_{t}=\varphi p\left(w_{t}\right) n_{t}
$$

which agents do not take into account when deciding on the number of children due to their atomistic behaviour. First-order condition (4.b) becomes

$$
\gamma c_{t}^{y}=(1-\varphi) p\left(w_{t}\right) n_{t}
$$

A child allowance lowers the marginal costs of raising a child, so people will decide to have more children and save less; both effects decrease the capital-labour ratio.

\footnotetext{
${ }^{8}$ Empirical evidence suggests that child allowances indeed have a significant (though moderate) positive effect on fertility choice (see e.g. Blanchet and Ekert-Jaffé, 1994, and Vallés Giménez and Marco, 2002, for Spain).

${ }^{9}$ Empirical evidence on the negative effect of PAYG-pensions on savings can be found in e.g. Feldstein (1996).
} 
This implies that future generations have a smaller capital stock to produce with, putting them at a disadvantage. The government therefore cannot confine to only one instrument, but needs an additional tool to achieve the socially optimal outcome. Since an unfunded social security scheme directly affects private savings (and thus the future capital stock), it serves as the additional instrument. This is in contrast to a small open economy, where the optimal child allowance follows from a given value of the PAYG-tax. More specifically, the following proposition shows that the choice of policy instruments crucially depends on the social discount factor.

Proposition 2 The optimal child allowance is given by $\varphi^{*}=\frac{\alpha(\delta+\beta \varepsilon)+\beta \varepsilon(\delta \alpha-1)}{\alpha(\delta+\beta \varepsilon)+(\gamma+\beta \varepsilon)(\delta \alpha-1)}$ and the optimal PAYG-tax by $\tau^{*}=\frac{\beta \varepsilon(1-\delta \alpha)-\alpha(\delta+\beta \varepsilon)}{(\delta+\beta \varepsilon)(1-\alpha)}$. Hence, if $\delta=\delta_{0} \equiv \frac{(1-\alpha) \beta \varepsilon}{\alpha(1+\beta \varepsilon)}$, the market solution coincides with the command optimum and no government intervention is required. If $\delta<\delta_{0}$, both a child allowance and PAYG-pensions are needed to achieve the first-best outcome. The child allowance amount corresponds to the present value of the public pension benefit, i.e. $\varphi^{*} p\left(w^{*}\right)=\tau^{*} w^{*} / r^{*}$. If $\delta>\delta_{0}$, a tax on children and transfers from the old to the young are required.

\section{Proof See Appendix.}

For a certain value of the social discount rate, government intervention is not required because the positive and negative social externalities of a child cancel out. If the discount rate is below that value, current young and future generations have a relatively low weight in the social welfare function compared to the currently retired, so for a given level of fertility, the government wants to increase old-age consumption relative to that of young workers (cf. eq. 9.c). In order to do so, a PAYG-scheme is introduced. This implies a net positive social externality of a child, which the government internalises through a child allowance scheme. This raises the number of children and reinforces the initial effect that follows from (9.c). The introduction of the PAYG-pension scheme has a negative impact on savings, which in combination with the increase in fertility, implies a strong decrease in the capital-labour ratio and low child raising costs. According to equation (9.b) this corresponds to an increase in fertility relative to young-age consumption, and this is exactly what is realised through the child allowance scheme. Inspection of (9.a) implies that in steady state, we have $\delta=n /\left(r+n p^{\prime} k f^{\prime \prime}\right)$. This basically says that the social planner equates the intertemporal marginal rate of substitution $(\delta)$ to the intertemporal marginal rate of 
transformation, $n /\left(r+n p^{\prime} k f^{\prime \prime}\right)$, which is affected by changes in fertility and the social return to capital. The latter consists of the interest rate minus the increase in the costs of children that results from a rise in the capital-labour ratio. The severe drop in the capital-labour ratio implies that the interest rate rises sharply. It is this rather strong general-equilibrium effect that causes a low value of $\delta$ to go along with a high fertility rate, so a child allowance scheme is required.

This is opposite to the case of a small open economy (see Groezen et al., 2003). In such an open economy, the social planner wants to set the fertility rate such that $n / \bar{r}=\delta$, where $\bar{r}$ is the interest rate exogenously given for a small open economy. Hence, the relation between the social discount factor and the rate of fertility is straightforward: instead of child allowances and public pensions, the government needs a tax on children and lump-sum transfers from the old to the young if the social discount rate is below the rate at which no intervention is required.

If, however, the conclusion is that the government should stimulate fertility, then the optimal policy in both a small open economy and a closed economy is to implement a child allowance that is equal to the present value of the public pension benefit.

Note that, although $k$ as well as $k^{*}$ are a function of $\lambda$, both $\tau^{*}$ and $\varphi^{*}$ are independent of this parameter. That is, the relation between the wage rate and the costs of a child affects both the capital-labour ratio that results without government intervention and the optimal capital stock per worker, but both to the same extent, so that the optimal PAYG-tax and child allowance is not affected. Furthermore, the optimal PAYG-tax does not depend on the utility weight of raising children $(\gamma)$.

\section{Optimal policy in an ageing society}

In light of the ageing of the populations in many countries, it is interesting to analyse not only how the optimal pension policy changes, but also how the appropriate child allowance is affected. Because people live longer, the savings and fertility decision is affected, which subsequently has implications for optimal government policy, as stated by the following proposition.

Proposition 3 Increasing longevity implies a higher optimal child allowance if 1 $\alpha-\alpha \delta>0$, and a higher optimal PAYG-tax.

Proof Differentiating $\varphi^{*}$ for $\varepsilon$ gives $\frac{d \varphi^{*}}{d \varepsilon}=\frac{\gamma(1-\alpha \delta)(1-\alpha-\alpha \delta)}{[\alpha(\delta+\beta \varepsilon)+(\gamma+\beta \varepsilon)(\alpha \delta-1)]^{2}}$, which is positive if 
$1-\alpha-\alpha \delta>0$. Differentiating $\tau^{*}$ for $\varepsilon$ gives $\frac{d \tau^{*}}{d \varepsilon}=\frac{(1-\alpha \delta) \beta \delta}{(1-\alpha)(\delta+\beta \varepsilon)^{2}}>0$

So for realistic values of the production parameter $\alpha$, population ageing (caused by a longer lifespan) means that the optimal child allowance increases.

Suppose that the PAYG-tax, the child allowance and the capital-labour ratio are optimal for a given value of $\varepsilon$. Then, if $\varepsilon$ rises, people live longer in retirement, so they decide to save more and have fewer children in their first period of life in order to prevent a too large drop in old-age consumption. This implies that the capitallabour ratio rises and reaches a suboptimally high level. In order to correct this, the government both raises the PAYG-tax (which means lower savings) and increases the child allowance (and thus raises fertility).

\section{Conclusion}

Dealing with the (adverse) consequences of population ageing involves more than merely reforming the public pension scheme. As a matter of fact, the most direct way would be to battle one of the causes of ageing itself: a lower fertility rate, which is clearly the result of individual deliberation. This paper had a closer look at fertility as the endogenous source of population growth, and thereby of the implicit return of a PAYG-financed social security scheme, in a closed economy. It was found that one form of ageing, increasing longevity, may incite a lower number of children, thus aggravating the ageing problem, but that the general-equilibrium effects of the resulting increase in the capital-labour ratio may lead to the opposite result. Furthermore, offspring causes three externalities on society that individuals do not take into account. A government can internalise all these externalities by implementing a program that effectively lowers the individual costs of rearing children, such as a system of child allowances, study grants and child care, so as to bring the fertility rate to its optimal level. It was shown that PAYG-pensions and child care are Siamese twins in a closed economy just like they are in an open economy. However, contrary to the open economy, both the optimal level of child care and the optimal PAYG-tax fall if the social discount factor is increased.

Implementing a program that lowers the costs of rearing children is an effective, relatively easy and politically achievable way of reducing the risk of the demographic time bomb in economies with extensive PAYG-schemes. Only focusing on reforming 
the pension scheme is not sufficient; the need for an appropriate child allowance scheme becomes more urgent as the optimal level of child allowances increases in a closed economy where people grow older. Neglecting this part of social security will thus result in greater welfare losses.

\section{Appendix}

\section{The market outcome}

In steady state, the individual number of offspring and savings with a child allowance scheme follow from combining (1.a') with (4.a), (4.b') and (10),

$$
n=\frac{\gamma(1-\tau) w r}{(1+\gamma+\beta \varepsilon) p(w) r-\gamma \tau w}, \quad s=\frac{(1-\tau) w[\beta \varepsilon p(w)(1-\varphi) r-\gamma \tau w]}{(1+\gamma+\beta \varepsilon) p(w) r-\gamma \tau w} .
$$

Capital market equilibrium implies $n k=s$. With $f(k)=k^{\alpha}$ and $p(w)=\lambda w$, the resulting equilibrium capital-labour ratio is

$$
k=\left(\frac{\gamma[\alpha+\tau(1-\alpha)]}{\alpha(1-\alpha) \beta \varepsilon \lambda(1-\varphi)}\right)^{1 /(\alpha-1)} .
$$

\section{The social optimum}

The first-order conditions for a social planner follow from maximising the social welfare function (7) subject to the resource constraint (8), resulting in first-order conditions (9.a-c). Substituting these equations into the economy's resource constraint gives the optimal capital-labour ratio,

$$
k^{*}=\left(\frac{\gamma+\beta \varepsilon-\alpha(\delta+\beta \varepsilon+\delta \gamma+\delta \beta \varepsilon)}{\alpha(1-\alpha) \lambda(\delta+\beta \varepsilon)}\right)^{1 /(\alpha-1)} .
$$

The policy instruments are chosen such that the first order conditions in a market setting, as given by (4.a-b'), are equal to those of a social planner. The optimal child allowance follows from equating (4.b') to (9.b). Combining this with (A.2) results in the optimal child allowance,

$$
\varphi^{*}=\frac{\alpha(\delta+\beta \varepsilon)+\beta \varepsilon(\delta \alpha-1)}{\alpha(\delta+\beta \varepsilon)+(\gamma+\beta \varepsilon)(\delta \alpha-1)} .
$$

Combining (A.1), (A.2) and (A.3) gives the optimal PAYG-tax,

$$
\tau^{*}=\frac{\beta \varepsilon(1-\delta \alpha)-\alpha(\delta+\beta \varepsilon)}{(\delta+\beta \varepsilon)(1-\alpha)} .
$$


Hence, $\varphi^{*}=\tau^{*}=0$ if $\delta=\delta_{0} \equiv \frac{1-\alpha}{\alpha} \frac{\beta \varepsilon}{1+\beta \varepsilon}$. Using (A.2) it can easily be seen that $\varphi^{*} p^{*}=\varphi^{*} \lambda w^{*}=\tau^{*} w^{*} / r^{*}=\tau^{*} w^{*} / \alpha k^{*(\alpha-1)}$.

Furthermore, $\frac{d \varphi^{*}}{d \delta}=-\frac{\alpha \gamma(1+\alpha \beta \varepsilon)}{[\alpha(\delta+\beta \varepsilon)+(\gamma+\beta \varepsilon)(\delta \alpha-1)]^{2}}<0$ and $\frac{d \tau^{*}}{d \delta}=-\frac{\beta \varepsilon(1+\alpha \beta \varepsilon)}{(\delta+\beta \varepsilon)^{2}(1-\alpha)^{2}}<0$. 


\section{References}

[1] Becker, G.S. (1961) "An Economic Analysis of Fertility" in NBER, Demographic and Economic Change in Developed Countries Princeton: Princeton University Press.

[2] Becker, G.S. and R.J. Barro (1988) "A Reformulation of the Economic Theory of Fertility" Quarterly Journal of Economics 103: 1-25.

[3] Blanchet, D. and O. Ekert-Jaffé (1994) "The Demographic Impact of Family Benefits: Evidence from a Micro-Model and from Macro-Data" in J. Ermisch and N. Ogawa (eds.) The Family, the Market and the State in Ageing Societies Oxford: Clarendon Press.

[4] Cigno, A. (1992) "Children and Pensions" Journal of Population Economics 5: 175-183.

[5] Cigno, A. (1993) "Intergenerational Transfers without Altruism" European Journal of Political Economy 9: 505-518.

[6] Cigno, A. and F.C. Rosati (1996) "Jointly Determined Savings and Fertility Behaviour: Theory, and Estimates for Germany, Italy, UK and USA" European Economic Review 40: 1561-1589

[7] Cigno A., L. Casolare, and F.C. Rosati (2003) "The Impact of Social Security on Saving and Fertility" Finanzarchiv 59: 189-211.

[8] Eckstein, Z. and K.I. Wolpin (1985) "Endogenous Fertility and Optimal Population Size" Journal of Public Economics 27: 93-106.

[9] Feldstein, M. (1996) "Social Security and Saving: New Time Series Evidence" National Tax Journal 49: 151-164.

[10] Folbre, N. (1994) "Children as Public Goods" American Economic Review 84: 86-90.

[11] Galor, O. and D.N. Weil (1996) "The Gender Gap, Fertility, and Growth" American Economic Review 86: 374-387. 
[12] Groezen, B. van, L. Meijdam and T. Leers (2002) "The Vulnerability of Social Security when Fertility is Endogenous" Journal of Institutional and Theoretical Economics 158: 715-730.

[13] Groezen, B. van, L. Meijdam and T. Leers (2003) "Social Security and Endogenous Fertility: Pensions and Child Allowances as Siamese Twins" Journal of Public Economics 87: 233-251.

[14] Leibenstein, H.M. (1957) Economic Backwardness and Economic Growth New York: Wiley.

[15] Razin, A. and U. Ben-Zion (1975) "An Intergenerational Model of Population Growth" American Economic Review 65: 923-933.

[16] Sinn, H.W. (1997) "The Value of Children and Immigrants in a Pay-As-YouGo Pension System: A Proposal For a Partial Transition to a Funded System" CEPR Discussion Paper 1734.

[17] Sinn, H.W. (2004) "The Pay-As-You-Go Pension System as a Fertility Insurance and Enforcement Device" Journal of Public Economics, 88: 1335-1357.

[18] Vallés Giménez, J. and A. Zárate Marco (2002) "Do Child Tax Allowances and Social Benefits Affect the Decision to Have Children? An Empirical Study in Spain" Estudios sobre la Economia Española 149.

[19] Zhang, J. (1995) "Social Security and Endogenous Growth" Journal of Public Economics 58: 185-213.

[20] Zhang, J. and J. Zhang (1998) "Social Security, Intergenerational Transfers, and Endogenous Growth" Canadian Journal of Economics 31: 1225-1241. 